\title{
Spatial Content and Motoric Significance
}

\author{
Robert Briscoe \\ Department of Philosophy \\ Ohio University \\ rbriscoe[]gmail.com \\ Received December 2013; accepted September 2014; published Autumn 2014.
}

\begin{abstract}
According to “actionism” (Noë 2010), perception constitutively depends on implicit knowledge of the way sensory stimulations vary as a consequence of the perceiver's self-movement. My aim in this contribution is to develop an alternative conception of the role of action in perception present in the work of Gareth Evans using resources provided by Ruth Millikan's biosemantic theory of mental representation.
\end{abstract}

Keywords: enactivism; egocentric spatial representation; visuomotor control; biosemantics; Gareth Evans.

\section{Introduction}

The sensorimotor contingency theory of perception (O’Regan \& Noë 2001, Noë 2004, Noë 2010, O’Regan 2012) or “actionism,” as it had been more recently called, is central to numerous enactivist projects in the philosophy of mind and cognitive science. ${ }^{42}$ According to actionism, perceptual experience constitutively depends on knowledge of the way sensory stimulation varies as a result of self-initiated, bodily movement. "For something to be visible," Alva Noë writes, “...is for it to show up as standing to us in a relation of, as I will put it, sensorimotor perturbability. If you see something, then movements of your eyes or body will affect the way you experience it" (2010: 248). Actionism it is important to emphasize, however, distances itself from the idea that vision is for action, that vision is functionally dedicated, in whole or in part, to the guidance of spatially directed bodily movement: "actionism does not claim that visual awareness depends on visuomotor skill, if by 'visuomotor skill' one

\footnotetext{
${ }^{42}$ Enactivism isn't so much a single, unified research perspective as it is a cluster of more or less closely related explanatory frameworks and philosophical methodologies, including but not limited to noncomputational and nonrepresentational dynamical systems theory, embodied cognitive science, ecological psychology, vehicle externalism, naïve realism, and certain forms of existential phenomenology.
} 
means the ability to make use of vision to reach out and manipulate or grasp. Our claim is that seeing depends on an appreciation of the sensory effects of movement (not, as it were, on the practical significance of sensation).... Actionism is not committed to the general claim that seeing is a matter of knowing how to act in respect of or in relation to the things we see" (Noë 2010: 249). ${ }^{43}$ To experience the three-dimensional shape, size, or orientation of a rock on the beach, on this view, it thus isn't necessary to understand, in a practical sense of understanding, how you would need to move your body if it were your purpose, say, to approach the rock, or to reach for it, or to pick it up in a certain way, or even to look in its direction. What is necessary, rather, is to understand how retinal stimulations caused by the light reflected from rock would change were you to act in any of these or other ways. ${ }^{44}$ For the

\footnotetext{
${ }^{43}$ There are at least two distinct senses in which seeing could be for action. Seeing could be for action in the sense that one of its psychological-kind-individuating functions is to guide visuomotor actions, e.g., by supplying motor programming system with information about the spatial properties of visible objects. Alternatively (and much less plausibly), vision could be for action in the sense that action guidance is its only function. Actionism denies that seeing is for action in either sense. I am grateful to any anoymous referee for prompting me to make this point.

${ }^{44}$ One source of empirical evidence for this view comes from studies of visuomotor development in the absence of normal, reafferent visual stimulation. Held \& Hein 1963 performed a now famous experiment in which pairs of kittens were harnessed to a carousel in a cylindrical chamber. One of the kittens in each pair was harnessed in such a way that it was able to engage in free circumambulation. The other kitten was suspended in the air in a metal gondola. When the first kitten walked, both kittens moved in a circle and received identical visual stimulation. However, only the first kitten received reafferent visual feedback as the result of self-movement. Held and Hein reported that only mobile kittens developed normal depth perception-as evidenced by their unwillingness to step over the edge of a visual cliff. Noë (2004) argues that this experiment supports the enactive approach: in order to develop normal visual depth perception, cats and other animals have to learn the sensory consequences of their own movements.
}

There are reasons to be skeptical of this assessment. For one thing, there is evidence that passive transport in the gondola may have disrupted the development of the kittens' innate paw placing responses to visually perceived surfaces (Ganz 1975: 206). Second, the fact that passive kittens were prepared to walk over the edge of a visual cliff doesn't show that their visual experience of depth was abnormal. Rather, as Jesse Prinz (2005) points out, it may only indicate that they "did not have enough experience walking on edges to anticipate the bodily affordances of the visual world." Evidence for this interpretation comes from studies of visual space perception in human infants. Campos et al. 1992 found that infants, ranging from 6.5 to 8.5 months, exhibit wariness of heights when lowered onto the deep side of a visual cliff only when they had prior experiences of crawling or using a walker. There is no empirical reason to think, however, that pre-locomotor infants in this age cohort are unable to perceive three-dimensional spatial layout (Campos 2000). Indeed, the available evidence suggests that just the opposite is the case (for a review, see Kellman \& Arterberry 2006). By one month of life, infants will blink defensively when presented with optical expansion patterns that normally signify an approaching object (Nanez \& Yonas 1994); by the end of the fourth month, binocular disparity is operative (Braddick \& Atkinson 1983); and by the seventh month, infants, regardless of previous locomotor experience, are sensitive to the "pictorial" cues of occlusion, familiar size, and height in the visual field, as evidenced by their visually guided reaching behavior (Granrud \& Yonas 1984, Granrud et al. 1985, Arterberry 2008). Summarizing decades of developmental evidence, Kellman and Arterberry write: "Before craw- 
actionist, the possession of visuomotor skill or "know-how" isn't required for visual awareness of the way objects fill out surrounding space.

I have elsewhere engaged in detailed criticism of the actionist approach (Briscoe 2008a, Briscoe forthcoming, Briscoe and Grush in preparation). Like a number of other philosophers, I am skeptical both about its internal coherence and empirical tenability (Block 2003, 2005, 2012; Prinz 2006, 2012; Matthen 2006; Schwitzgebel 2006; Clark 2009, 2012). I won't attempt to summarize the state of the debate here. My aim, instead, is to lay out an alternative conception of the role of action in perception present in the work of Gareth Evans (1982, 1985), one that I think is far more consistent with mainstream empirical research in perceptual psychology and cognitive neuroscience and that has yet to be developed, I think, in a sufficiently careful and systematic way. Unlike proponents of actionism, Evans does not look to knowledge of the proximal sensory consequences of movement in order to explain how perception acquires its spatial content. Rather, he looks to the functional role played by perception in adapting the agent's bodily actions to the spatial layout of the distal environment. Unlike actionism, Evans' theory is committed to the claim that "seeing is a matter of knowing how to act in respect of or in relation to the things we see" and, so, to the constitutive dependence of visuospatial awareness on the possession of visuomotor skill.

Here is an overview of the rest of this paper. In section 2, I present an interpretation of four claims central to Evans's theory of the egocentric spatial content of perception. I also answer objections to Evans's theory that arise from a failure to distinguish between the objective spatial content of a perceptual experience and the experience's motoric significance for the perceiving subject. In section 3, I then show that Evans' theory can be helpfully elaborated using resources provided by Ruth Millikan's biosemantic theory of mental representation.

\section{Evans on the role of action in perception}

The idea that action and perception are closely related is neither new, nor especially radical. Many philosophical and psychological theories of vision in the last 300 years have looked to capacities for embodied, visuomotor action to explain how visual experience acquires its spatial representational content (for a review, see Briscoe and Grush in preparation). One historically important source of motivation for this approach is the empiricist doctrine that

ling, infants perceive depth; what may change with crawling experience is the coordination of depth and surface perception with their own motion in space” (1998: 261). An analogous conclusion can plausibly be drawn with respect to Held and Hein's kittens. 
vision must be "educated" by the sense of touch-understood as including both kinaesthesis and proprioceptive position sense-if the former is to acquire its outward, three-dimensional spatial significance. Normal vision, Berkeley influentially argued in his New Theory (1709/2008), results only when tangible ideas of distance (derived from experiences of unimpeded movement) and solid shape (derived from experiences of contact and differential resistance) are elicited by the visible ideas of light and color with which they have been habitually connected. A long line of philosophers including Condillac, Reid, Smith, Mill, Bain, and Dewey accepted the basics of Berkeley's account of the relation between sight and touch.

A second important source of motivation for action-oriented approaches to perception is teleological. From an biological or evolutionary standpoint, it is reasonable to think that vision is for action, that its preeminent biological function is to adapt an animal's bodily movements to the properties of the environment that it inhabits. This view is widely accepted in the neuroscience of visuomotor control: "the functional organization of the visual system (like the rest of the brain)," Melvyn Goodale writes, "has been ultimately shaped by the role it plays in the control of movement" (Goodale 2011: 1568). It is also clearly reflected in externalist or "anti-individualist" approaches to perceptual content in the philosophy of mind. "The representational content of an animal's perceptual states," as Tyler Burge puts it, "is individuated partly in terms of what causes those states and how those states enable the animal to cope with specific types entities in its environment. Successful interactions help ground individuation of perceptual states partly in terms of representational content" (2005: 5). Seeing, of course, subserves a variety of other important purposes besides the guidance of actions-its contents are both directive and descriptive (Millikan 2004) - but this is plausibly one of its biologically central and psychological-kind-individuating functions.

Yet a third source motivation comes from skepticism about the explanatory adequacy of alternative approaches. Most philosophers of mind, it is fair to say, now concur that representation is a functional kind. A mental state is a vehicle of representation content only if it used in certain ways, only if it plays a certain role in the agent's cognitive economy. It seems unlikely, however, that perceptual states acquire spatial contentfulness in virtue of their role in propositional inference (for instance, in propositional, spatial reasoning). Indeed, capacities for propositional inference seem neither necessary nor sufficient for perceptual spatial representation. They don't seem necessary because young human infants and many animals that lack capacities for propositional inference are evidently three-dimensional space perceivers. And they don't seem sufficient because there are good reasons to think that the spatial content of perception is, in general, nonconceptual-and, so, constitutively independent of having capacities for propositionally articulated 
reasoning (for discussion, see the essays collected in Gunther 2003, Bermúdez 2007, and Burge 2010, chap. 11).

In Chapter 6 of The Varieties of Reference (1982), Gareth Evans argues that perceptual states acquire their nonconceptual spatial contents in virtue of the role they play in the guidance of spatially directed motor actions. The approach Evans develops is structured by four main claims:

(1) The spatial content of perceptual experience is subject-relative or "egocentric" (if not exclusively so). "The subject hears the sound as coming from suchand-such a position, but how is the position to be specified? Presumably in egocentric terms.... These terms specify the position of the sound in relation to the observer's own body" (1982: 155).

(2) We perceive egocentric spatial properties using the same spatial coding system or "frame of reference" as is used for purposes of forming and implementing our intentions for object-directed bodily actions. "Egocentric spatial terms are the terms in which the content of our spatial experiences would be formulated, and those in which our immediate behavioral plans would be expressed" (1982: 154).

(3) Our perception of an object's egocentric spatial properties is constitutively connected with having certain dispositions to engage in bodily actions targeted on or otherwise directed in relation to the object. "[W]e must say that having spatially significant perceptual information consists at least partly in being disposed to do various things" (1982: 155).

(4) Perceptual information about an object's position in egocentric space is not information about a special kind of space, but rather information of a special kind about space. "It is perfectly consistent with the sense I have assigned to [egocentric spatial] vocabulary that its terms should refer to points in a public three-dimensional space" (1982: 157).

My aim in this section is to interpret these claims by clarifying them and relating them to one another. I shall also answer objections to Evans's account that arise, I suggest, from a failure to distinguish between the objective, egocentric spatial content of a visual experience and its motoric significance for the perceiving subject (Claim 4). Although I shall be focusing on the case of conscious vision, points made here are intended to generalize to other sensory modalities.

Let's begin with Claim 1. According to Claim 1, visual experience represents the egocentric spatial properties of visible objects and surfaces, that is, their spatial relations to the perceiving subject. Thus, when you see a plate on the table, you see among other things its direction and distance from your own body as well as its three-dimensional orientation relative to your line of sight. Claim 1, it is important to stress, does not exclude the possibility that visual experiences also represent various allocentric spatial properties and relations. 
E.g., in addition to seeing the plate's location relative to your own body, you may also see its position relative to a nearby fork and saltcellar.

Three remarks should be made about Claim 1. First, there is psychophysical evidence that at close range and under ecologically normal viewing conditions our ability consciously to perceive egocentric spatial layout is highly accurate. While perceived distances are significantly foreshortened for objects located more than 30 meters away, in what Cutting and Vishton (1995) call vista space, the egocentric distances of objects located up to 2 meters away, in personal space, are perceived with nearly metric accuracy. ${ }^{45}$ Although proponents of the dual systems model of visual processing (Milner \& Goodale 1995/2006, Goodale \& Milner 2004) have maintained that conscious vision does not make use of an egocentric spatial coding system, this claim, I would suggest, is flatly inconsistent with mainstream psychophysical work in perceptual psychology (see Briscoe 2008b, 2009 and Briscoe \& Schwenkler forthcoming).

Second, Claim 1 is a claim about the spatial contents of visual experienceabout which objective (but subject-relative) spatial properties are represented in visual experience-and as such does not by itself entrain any specific commitments about the system of egocentric spatial representation used to encode those contents. Indeed, possible perceptual mental representations with a given egocentric spatial content, as Christopher Peacocke points out, stand in a many-one relation to the content itself (1992: 65). Knowing which spatial properties are encoded by a system of spatial representation $S$ does not by itself tell us how those properties are encoded by $S$.

Third, Claim 1 by itself does not identify the location of the self or ego in relation to which egocentric spatial properties are supposed to be represented in visual experience. Indeed, it does not indicate whether there is a single, privileged locus in (or on) the body that counts as the center of visual egocentric space and, so, does not indicate whether the ego qua perceiving subject is literally a point of view-in the world only "geometrically," as John McDowell puts it $(1994,104)$. This means that, in addition to the leaving the nature of the spatial coding system used in visual experience indeterminate, Claim 1 also leaves indeterminate how that system is to be aligned with the perceiving subject's body.

Although this may seem like a straightforward phenomenological question, it is not. In fact, different philosophers influenced by Evans's account have given quite different answers to it. Christopher Peacocke (1992), for instance,

\footnotetext{
${ }^{45}$ The difference in precision is a function of the spatial information available to the visual system. Estimates of depth for objects in personal space are powerfully constrained by stereopsis, convergence, and accommodation. As distances lengthen, these binocular sources of depth information drop off in effectiveness, and the visual system must rely increasingly on somewhat less precise monocular or "pictorial" cues in the light sampled by the eyes.
} 
maintains that visual experiences represent the way visible surfaces are arrayed in three-dimensional space relative to a point placed in the subject's torso. By contrast, Jose Bermúdez (1998: 2005) identifies the ego at the center of visual egocentric space with the apex of the solid angle of the visual field, while Quassim Cassam (1997) identifies the ego with the living, acting body as a whole (what he calls the "bodily self").

One reason why visual phenomenology is not decisive here, I would suggest, is that there is disagreement about what counts as distinctively visual experience of space. In particular, when we say that we visually perceive the spatial relations in which certain objects stand to ourselves, what role does proprioception play in the representation of those spatial relations? Consider the case of seeing an object's (radial) direction. If Bermúdez is right, then visual experience only represents the object's direction from you relative to a point midway between your eyes. In this case, your representation of the tree's egocentric direction is fully independent of concurrent proprioceptive information, whether conscious or nonconscious, about the spatial configuration of the rest of your body.

Peacocke, by contrast, maintains that the directional axes used to specify the spatial content of a visual experience originate from a point in the center of the torso. "The appropriate set of labeled axes," he writes, "captures distinctions in the phenomenology of experience itself. Looking straight ahead at Buckingham Palace is one experience. It is another to look at the palace with one's face still toward it but with one's body turned toward a point on the right. In this second case the palace is experienced as being off to one side from the direction of straight ahead, even if the view remains exactly the same as in the first case" (1992: 62). The visual system, however, initially encodes an object's location relative to the eye (that is, in retinocentric coordinates). Representing an object's location in visual experience relative to the torso thus presupposes prior integration of visual information about the object's eye-relative location with proprioceptive information about the spatial configuration of the body, in particular, information about the direction of gaze and the orientation of the head. We could call this a "visuoproprioceptive" representation of the palace's direction.

Something similar, of course, seems possible in respect of other proprioceptively represented parts of the body, for example, the head, shoulder, or hand. If so, then there needn't be a single bodily locus that, in general, counts as you for purposes of characterizing your visually perceived spatial relations to an object. The ego at the center of perceptual egocentric space, as suggested by Cassam, may spread to encompass the body as a whole. ${ }^{46}$

\footnotetext{
${ }^{46}$ This does not assume that the perceiver is delivered in visual experience with a complete and uniformly detailed representation of an object's location relative to every part of her body at the
} 
I will not attempt to adjudicate between these different views here ${ }^{47}$ It is enough to point out that which egocentric spatial relations one takes to be represented in visual experience depends on where one locates the ego at the center of visual egocentric space, and this, in turn, depends in part on how one conceives of the relationship between conscious vision and bodily proprioception.

Claim 1 was a claim at the level of objective spatial representational content. Claim 2, by contrast, is a claim at the level of spatial representational format. According to Claim 2, we perceive egocentric spatial properties using the same spatial coding scheme as is used for purposes of forming and implementing our intentions for spatially directed movement and action. As Evans puts it, "Egocentric spatial terms are the terms in which the content of our spatial experiences would be formulated, and those in which our immediate behavioral plans would be expressed" (1982: 154).

One motivation for Claim 2 is presumably that, in order to form intentions for bodily actions directed in relation to an object, it is necessary to locate the object's position in three-dimensional space relative to the current location of one's own body (or parts thereof). E.g., in order to pick a peach it is not sufficient to have allocentric information about the peach's location relative to the rest of the scene, you must also have egocentric information about its position relative to the current location of your hand. It is in this sense, to a first approximation, that both perception and action make use of a common, egocentric way of representing objects in space.

As an aside, I should mention that it does not follow from the fact that it is possible to specify an object's perceived position in egocentric space using the subject-centered axes left/right, above/below, and in front of/behind that a spatial coding system based on these axes is actually used to plan actions directed in relation to the object. Indeed, behavioral and neurophysiological studies rather suggest that visuomotor activity is typically subserved by a variety of coordinated, effector-specific spatial coding systems, some of which represent object locations not in extrinsic, directional terms, but rather in intrinsic, kinematic terms (Scott 2008, Kalaska 2009).

same time. The idea is rather that, when she perceives an object's position in visual egocentric space, it may be any part of her body of which she is proprioceptively aware in relation to which the object's position is perceived. See Briscoe 2009: 425-426.

${ }^{47}$ Although I think that a verdict here should be based, in part, on a theory's ability to explain the phenomenon of visual direction constancy. E.g., Peacocke must explain why the tree's direction appears stable when I maintain fixation on the tree, but rotate my torso to the right, if the tree's unchanging position relative to my eyes is not also represented in visual experience. See Wu 2014 for a recent argument that the experience of visual direction constancy requires an encoding of perceived object locations in one or more non-retinocentric, egocentric frames of reference. 
Tim Crane (2009) points out that it does not follow from the fact that it is possible to describe the content of a perceptual experience using a proposition that the inner representational vehicle of that experience is itself propositional or sentence-like. I am making a similar point here about egocentric spatial representation. We need to distinguish between a specification of the objective content of an egocentric spatial representation $R$, which may be characterized using any geometrically adequate system of spatial representation, and a specification of the system of spatial representation actually used to construct $R$.

Let's turn to Claim 3. It deals, importantly, with the relationship between what we see and what we do. One way of interpreting Claim 3 would be as insisting that the egocentric spatial content of a visual experience is not constitutively independent of its motoric significance for the perceiving subject. By the motoric significance of a visual experience, I intend its functional role in planning spatially directed bodily actions in light of the agent's current motivations, beliefs, objectives, etc. There is a clear connection between this way reading Claim 3 and Jesse Prinz's recent proposal that conscious perceptual experience functions as a menu for action: "Consciousness makes information available for decisions about what to do, and it exists for that purpose” (Prinz 2012: 203).

Two remarks are important. First, Claim 3 connects having spatially significant perceptual information with having "dispositions to do various things." Why? One thought is that Evans intended to establish certain general, nonintentionally characterizable necessary conditions for perceptual spatial representation (see, e.g., Noë 2004, chap. 3). I think that this behaviorist interpretation of Evans's project in chapter 6 of The Varieties of Reference is mistaken. Evans, in several places, is explicit that dispositions to spatial behavior need not be directly induced by perceptual inputs, but may be, as he says, "conditional also on other beliefs and desires" (1982: 155, fn. 23). A subject, capable of reasoning, will be disposed to engage in an action directed in relation to certain a region of egocentric space only "when [her] thoughts make it appropriate” (1982: 161, fn. 33) or when it seems a "good thing to do" (1982: 161). She will not normally form a disposition to advance in the perceived direction of angry rattlesnake or to reach for a red-hot poker, for example, unless her circumstances provide her with compelling reasons to do so. In general, Evans' dispositions to spatial behavior appear to be propensities to respond to the spatial structure of the environment in ways that are intelligible in light of the subject's cognitive and motivational states. They are not dispositions to behavior in the sense of the classical behaviorist. What matters, for Evans, is knowing how to act in response to the perceptual inputs in ways that make rational sense. 
Second, it is important not to collapse the distinction between the egocentric spatial content of a visual experience and its motoric significance. Evans's view is not that the egocentric spatial content of a perceptual experience just is its "behavioral spatial purport," to use Rick Grush's (2007) term. It is one thing to specify the egocentric spatial content of a visual experience, say, that an object is located in a certain direction and at a certain distance in depth from the subject. It is quite another to provide an account of what makes it the case that, for any given egocentric spatial content, the subject is having a visual experience with that content and not some other. ${ }^{48}$ Evans's proposal is that such an adequately individuating account of the egocentric spatial contents of perceptual experience must advert to the subject's abilities to engage in bodily actions targeted on or otherwise directed in relation to environing objects and surfaces. Motoric significance is that in virtue of which visual experiences have objective, egocentric spatial content. This proposal, however, should not be taken to imply that the egocentric spatial content of a visual experience is identical to its motoric significance. The latter is not what we see when we have a visual experience with a certain spatial content. Rather, it is part of having a visual experience with that content and not some other. (Compare the proposal that a statement $S$ must play a certain inferential role in order to have the semantic property of being true just in case Edinburgh is east of Glasgow, but west of Oxford. This proposal clearly does not imply that $S$ 's truthcondition is in any sense identical to its role in inference.)

This, I take it, is the point Evans is making with Claim 4:

...when I speak of information "specifying a position in egocentric space," I am talking not of information about a special kind of space, but of a special kind of information about space-information whose content is specifiable in an egocentric spatial vocabulary. It is perfectly consistent with the sense I have assigned to this vocabulary that its terms should refer to points in a public threedimensional space (1982: 157).

The claim that the egocentric spatial content of a visual experience is determined by its motoric significance for the perceiving subject thus is a claim not about what the visual experience represents (it is not a claim at the level of reference), but a claim about the conditions under which a visual experience will have such content. When a subject perceives an object's egocentric location, the information about space in her possession is "special" because it is poised to guide her actions in relation to the object. It is consistent with this suggestion, however, that egocentric spatial properties represented in her perception are objective (if subject-relative) properties of things in public, three-dimensional space.

\footnotetext{
${ }^{48}$ This formulation is the perceptual analogue of Peacocke's "Discrimination Principle" for the conceptual contents of thought.
} 
A number of philosophers have failed adequately to enforce the distinction between egocentric spatial content and what I am calling motoric significance. For example, Adrian Cussins, in a discussion of the spatial content of auditory perception, writes:

Evans's idea is that the spatial content of the auditory perception has to be specified in terms of a set of conceptually unmediated abilities... to move in the egocentric space around the organism. This is because the content consists in the experiential availability to the subject of a dispositional ability to move. The experiential content of perception is specified in terms of certain fundamental skills which the organism possesses (1990: 397, emphasis added).

One natural objection to saying that the egocentric spatial content of a perceptual experience consists in having certain abilities to move one's body is that there are indefinitely many different ways in which a perceiver may elect to respond to the perceived spatial structure of the environment. As Mohan Matthen writes, "there is no such thing as the proper response, or even a range of functionally appropriate responses, to what perception tells us” (1988: 20). The egocentric spatial content of a visual experience, for Evans, however, does not consist "in the experiential availability to the subject of a dispositional ability to move." Motoric significance is that in virtue of which a visual experience has egocentric spatial content. It is not identical to (the same thing as) its egocentric spatial content.

John Campbell (2005) also seems to elide the egocentric spatial content of a visual experience with its motor significance in a discussion of Evans. According to Campbell, Evans's egocentric spatial representations identify the locations of objects "merely as affordances," as possible ways of moving and acting (2005: 200). Campbell rightly balks at this proposal: "The trouble with this gloss on the content of egocentric identifications of location is that we would ordinarily take spatial location to be the categorical basis of these affordances. That is, we think that it is the relative locations of the thing and the agent that explain why it is possible for the agent to act on the thing. We do not suppose that egocentric location is actually constituted by the possibility of the agent acting on the thing” (2005: 201).

Evans, however, on the interpretation offered here, does not collapse the distinction between what we see and what we do in this way. The point to emphasize is that egocentric spatial information is not information about a special kind of space, a space of Gibsonian affordances, but rather information of a special kind about space, information poised to guide actions that are sensitive to the spatial properties of the objects around us. The claim that "having spatially significant perceptual information consists at least partly in being disposed to do various things" (Evans 1982: 155) does not imply that such information is constituted by (or about) what one is disposed to do. It is having spatially significant perceptual information that, for Evans, partly consists in 
being disposed to do various things, not the information itself. As Jesse Prinz has forcefully argued, perceptual experience from a functional standpoint can be for action without being constituted by action (Prinz 2012: 211).

Last, if a "sensorimotor chauvinist," in Andy Clark's (2009) sense, is someone who maintains that any difference in the motor activities to which a perception may give rise constitutes a difference in the perception's content, then it is clear that Evans is not a sensorimotor chauvinist. He respects the distinction between the content of a representation and the use to which that representation is put by its motoric consumers. One implication is that different perceivers (even those belonging to different species) may, in principle, have visual experiences with the same egocentric spatial contents despite having very different motor skills. Thus, I and an orangutan may both see that a tree branch is, e.g., at certain orientation in depth even though the motoric significance of the orangutan's visual experience is no doubt very different than that of my own visual experience. It is a significant merit of the present interpretation of Evans's theory, I take it, that it enables Evans to sidestep the charge of sensorimotor chauvinism sometimes leveled against action-oriented approaches to the spatial contents of perceptual experience.

\section{Looking at Action-Oriented Represenation from a Biosemantic Perspective}

Ruth Millikan's biosemantic theory of mental representation (Millikan 1989, 1995, 2004), I would suggest, provides us with resources for developing Evans' approach with a bit more detail. According to the biosemantic theory, an item $R_{0}$ will function as a representation of some structured aspect of the distal environment $E_{0}$ only if two conditions obtain:

Guidance: $R_{0}$ 's function or purpose is to guide a consumer in the performance of some type of task $T$ (or a range of different types of tasks), where the consumer's successful performance of $T$ depends on the fact that $E_{0}$ obtains.

Systematicity: The way the consumer is guided by $R_{0}$ systematically depends on $R_{0}$ 's structure or composition, such that had some variant of $R_{0}$ $\left(R_{1}, \ldots R_{n}\right)$ been produced instead of $R_{0}$, then the consumer's way of performing $T$ would have proved successful only if instead of $E_{0}$ there had been some corresponding variant $\left(E_{1}, \ldots E_{n}\right)$.

The idea that perceptual awareness of viewer-relative spatial layout constitutively involves a kind of bodily readiness for action-Claim 3 above-can be elaborated using versions of these two conditions. Assume that $R_{0}$ was produced by a perceptual input system of some kind. Then, $R_{0}$ will represent the 
instantiation of a determinate egocentric spatial property $G_{0}$, e.g., a certain viewpoint-relative distance or direction, by an object $O$ only if:

Motor Guidance: $R_{0}$ 's function or purpose is to guide motor consumers in the performance of some type of action $A$ (or a range of different types of actions), where successful performance of $A$ depends on the instantiation of $G_{0}$ by $O$.

Motor Systematicity: The way motor consumers are guided by $R_{0}$ systematically depends on $R_{0}$ 's structure or composition, such that had some variant of $R_{0}\left(R_{1}, \ldots R_{n}\right)$ been produced instead of $R_{0}$, then their way of performing $A$ would have proved successful only if instead of instantiating $G_{0}$ some corresponding determinate of the same determinable property $\left(G_{1}, \ldots G_{n}\right)$ had been instantiated by $O$.

We can consider these two requirements in relation to a toy model of how connectionist neural networks handle the problem of sensorimotor coordination devised by Paul Churchland (1986, 2012). The model involves a virtual, robotic crab with a two-jointed moveable arm and eyes that can rotate $90^{\circ}$ from side to side (Figure 1). The crab represents the location $(x, y)$ of an object in front of it using a sensory activation vector $\left(\alpha_{i}, \beta_{i}\right)$, where $x$ and $y$ specify the object's placement in a two-dimensional coordinate system centered on the hinge of the crab's shoulder and where $\alpha_{i}$ and $\beta_{i}$ are the input activation levels corresponding, respectively, to the rotation angles $\alpha$ and $\beta$ of its left and right eyes.

The crab's task is to move its arm so as to position the tip of its pincer on the $(x, y)$ coordinates of a reachable object $O$. That arm position will require the crab's shoulder and elbow to assume a pair of angles $(\theta, \phi)$. For example, if $O$ is located at the point encoded by eye-angles $\left(62^{\circ}, 98^{\circ}\right)$, then the crab's shoulder and elbow joints must assume the angle pair $\left(60^{\circ}, 47^{\circ}\right)$. In order to perform this task, the crab's neural network is trained to transform the eye-angle input vector $\left(\alpha_{i}, \beta_{i}\right)$ into a motor output vector $\left(\theta_{o}, \phi_{o}\right)$, where $\theta_{o}$ is output activation level corresponding to the shoulder angle $\theta$ and $\phi_{o}$ is the output activation level corresponding to the elbow angle $\phi$.

It is easy to see that Churchland's crab meets the Motor Guidance requirement: a given eye-rotation-angle activation pair in the crab's input layer $\left(\alpha_{i}, \beta_{i}\right)$ represents the distal location $(x, y)$ of an object $O$ because the vector's function is to guide the way the crab reaches toward $O$, and the crab will only reach toward $O$ successfully only if $O$ is situated at $(x, y)$. The crab also meets the Motor Systematicity requirement: For any reachable location $(x, y)$, there is a corresponding vector $\left.\left(\alpha_{i}, \beta_{i}\right)\right)$ in the crab's sensory input layer. To each such input vector, in turn, there is a corresponding vector $\left(\theta_{o}, \phi_{0}\right)$ in the crab's motor output layer that will guide the tip of the crab's pincer to $(x, y)$. In other 
words, variations in $O$ 's distance and direction systematically give rise to variations in sensory input which, in turn, systematically give rise to variations in object-directed motor output. There is a one-to-one mapping from points in objective space to points in visual space to points in motor space.

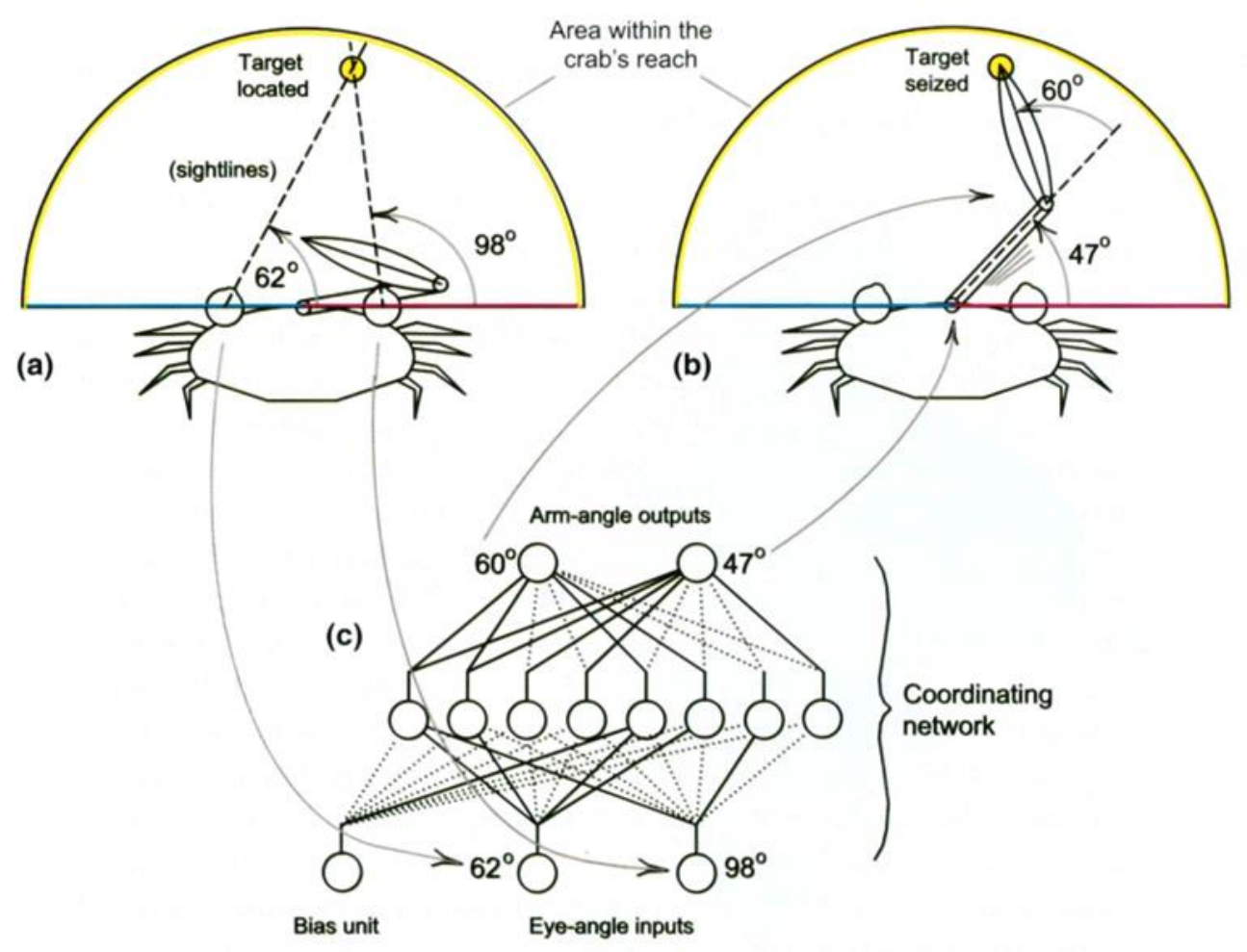

Figure 1. A robotic crab with an extendable arm and rotatable eyes

From Paul Churchland. 2012. Plato's Camera: How the Physical Brain Captures a Landscape of Abstract Universals. Plate 3 @ Massachusetts Institute of Technology, by permission of The MIT Press.

I will close with a few brief remarks about this example. First, the robotic crab example is deliberately simple. Besides having more sophisticated perceptual systems, real-world sensorimotor agents typically have a wide array of controllable body parts, access to proprioceptive/kinaesthetic information concerning their movements, and the ability to select goals and types of actions to perform on the basis of their beliefs and current needs.

When we scale up, in particular, when the way consuming motor systems respond to inputs from perceptual producers in guiding actions depends, in part, on belief- and desire-sensitive practical reasoning, there will be no simple relationship between sensory inputs and motor outputs. Hence, as Matthen says, there will be no such thing as the functionally proper response to what is perceived. (Indeed, much of the time, the correct response to the 
representation will be to do nothing at all, to ignore the bit of reality that the representation reveals.)

This is not a problem for the approach sketched here. For purposes of contentindividuation, what is important from the standpoint of the biosemantic interpretation of Evans' theory is not uniformity in the effects a perceptual representation has on its consumers, but rather uniformity in the worldly condition under which consumer responses, however diverse these may be, will prove successful. As Millikan writes, "if the position of the chair in the room does not correspond, so, to my visual representation of its position, that will hinder me equally in my attempts to avoid the chair when passing through the room, to move the chair, to sit in it, to remove the cat from it,... etc.” (Millikan 1989: 289).

Perception and action, then, although less closely linked, are not decoupled in sophisticated sensorimotor agency. For any determinate, spatial property $G$, there will be indefinitely many different ways in which the agent might respond to the experience of $G$ 's instantiation by an object in her field of view. What matters to Evans' approach, as reconstructed in this section, however, is not which of various possible actions the agent actually selects for performance. Rather, what matters is that the agent's visual experience is poised to guide a range of actions directed in relation to the object and that the way any given action in the range is performed depends for its success on $G$ 's being instantiated. When an experience is poised in this way, it equips the agent with the practical know-how needed to interact with the object in $G$-sensitive ways.

The second point is that such know-how need not be implemented in order to have the experience in question. Having the experience is dependent on having the capacity to perform $G$-sensitive actions rather than on its overt actualization (see Schellenberg 2007 for discussion of this idea). What matters to seeing an object's direction, for example, is not acting on one's capacity to walk (or run or crawl) in its direction, but knowing how one would have to move one's body in order to do so. Evans' theory does not have the implausible implication that an agent who is paralyzed or unable to move her bodysay because she has been buried up to her neck in sand-is thereby unable perceive the spatial attributes of the objects that surround her. So long as she has the right sort of practical know-how, she qualifies as a fullyfledged space perceiver.

Third, the distinction between an experience's objective spatial content and its motoric significance for the perceiving subject (Claim 4) can be clearly drawn within the biosemantic framework: the spatial content of a given perceptual representation-in the crab example, this representation will be a given sensory input vector $\left(\alpha_{i}, \beta_{i}\right)$-is not identified with the functions or activities performed by its "downstream" motoric consumers, with what its motoric con- 
sumers do. Rather, it is identified with the way the world needs to be if the representation's motoric consumers are to perform their functions successfully-here the way object $O$ must be situated in front of the crab if the $\left(\alpha_{i}\right.$ $\left.\beta_{i}\right) \rightarrow\left(\theta_{o}, \phi_{o}\right)$ transformation is to result in successful reaching.

It is thus possible to maintain that perceptual representations acquire spatial significance in virtue of their functional role in guiding actions without collapsing the distinction between the way the distal world is represented as being in perception and the subject's motoric responses to the world. Objects are not represented merely as things that can be acted upon thus-and-so, but as having the intrinsic and relational spatial properties that afford possibilities for action.

Finally, human perceptual systems produce representations that are not limited in their function to action-guidance, but that also play a role in high-level object recognition, imaginative problem-solving, and intersubjective communication. As Noë argues, it would thus be "dogmatic to suppose that the only aim of vision is action" (2010: 248). The Motor Guidance requirement, however, does not entail commitment to this dogmatic supposition. To insist that the spatial content of a perceptual state derives from the state's functional role in action-guidance is not to deny that the state may serve a wide variety of other purposes as well. The Motor Guidance requirement in no way precludes a role for space-representing perception in forms of problem-solving that are related only in a very indirect ways to negotiating and interacting with the threedimensional environment. Perceptual experience, from a functional standpoint, can be for action without being exclusively for action.

\section{Conclusion}

There is obviously much more that needs to be said about and in defense of Evans' approach to the relationship between action and perception. I have not said anything, in particular, about empirical objections to the approach premised on the dual systems model of visual processing (Milner \& Goodale 1995/2006; Clark 2001, 2007; Goodale \& Milner 2004). ${ }^{49} \mathrm{I}$ hope however to have shown in this brief treatment that there is a coherent alternative to actionism, one that looks to embodied interaction with the distal environment rather than to knowledge of the sensory consequences of movement to explain the spatial contentfulness of perceptual experience..$^{50}$

\footnotetext{
${ }^{49}$ But see Briscoe 2008b, 2009 and Briscoe \& Schwenkler forthcoming.

${ }^{50}$ For helpful discussion of an earlier version of this paper, I am grateful to James Genone and Wayne $\mathrm{Wu}$.
} 


\section{References}

Arterberry, M. 2008. Infants' sensitivity to the depth cue of height-in-the-pictureplane. Infancy,13: 544-555.

Berkeley, G. 1709/2008. An Essay towards a New Theory of Vision. In D. Clarke, ed. Berkeley: Philosophical Writings. Cambridge: Cambridge University Press.

Bermúdez, J. 1998. The Paradox of Self-Consciousness. Cambridge, MA: MIT Press.

Bermúdez, J. 2005. The phenomenology of bodily awareness. In D. W. Smith and A. Thomasson, eds. Phenomenology and Philosophy of Mind. Oxford: Oxford University Press.

Bermúdez, J. 2007. What is at stake in the debate on nonconceptual content? Philosophical Perspectives, 21: 55-72.

Block, N. 2005. Review of Action in Perception. Journal of Philosophy 102: 259-272.

Block, N. 2003. Tactile sensation via spatial perception. Trends in Cognitive Sciences 7: 285-286.

Block, N. 2012. Discussion of J. Kevin O'Regan's Why Red Doesn't Sound Like a Bell: Understanding the Feel of Consciousness. Review of Philosophy and Psychology 3: 89-108.

Braddick, O. \& Atkinson, J. 1983. Some recent findings on the development of human binocularity: A review. Behavioural Brain Research 10: 141-150.

Briscoe, R. 2008a. Vision, action, and make-perceive. Mind and Language 23: 457-497.

Briscoe, R. 2008b. Another look at the two visual systems hypothesis. Journal of Consciousness Studies 15: 35-62.

Briscoe, R. 2009. Egocentric spatial representation in action and perception. Philosophy and Phenomenological Research 79: 423-460.

Briscoe, R. forthcoming. Bodily action and distal attribution in sensory substitution. To appear in Sensory Substitution and Augmentation, edited by F. Macpherson, Proceedings of the British Academy, Oxford: Oxford University Press.

Briscoe, R. and Grush, R. in preparation. Action-based theories of perception. To appear in the Stanford Encyclopedia of Philosophy.

Briscoe, R. and Schwenkler, J. forthcoming. Conscious vision in action. To appear in Cognitive Science.

Burge, T. 2005. Disjunctivism and perceptual psychology. Philosophical Topics 33: 1-78.

Burge, T. 2010. Origins of Objectivity. Oxford: Oxford University Press.

Burge, T. 2005. Information-processing, phenomenal consciousness, and Molyneux's problem. In José Bermúdez, ed., Thought, Reference, and Experience: Themes from the Philosophy of Gareth Evans. Oxford: Oxford University Press.

Campos, J., Bertenthal, B., \& Kermoian, R. 1992. Early experience and emotional development: The emergence of wariness of heights. Psychological Science 3: 61-64. 
Campos, J., Anderson, D., Barbu-Roth, M., Hubbard, E., Hertenstein, M., \& Witherington, D. 2000. Travel broadens the mind. Infancy 1: 149-219.

Cassam, Q. 1997. Self and World. Oxford: Oxford University Press.

Churchland, P. 2012. Plato's Camera. Cambridge, MA: MIT Press.

Clark, A. 2001. Visual experience and motor action: Are the bonds too tight? The Philosophical Review 110: 495-519.

Clark, A. 2007. What reaching teaches: Consciousness, control, and the inner zombie. The British Journal for the Philosophy of Science 58: 563-594.

Clark, A. 2009. Supersizing the Mind. Oxford: Oxford University Press.

Clark, A. 2012. Dreaming the whole cat: Generative models, predictive processing, and the enactivist conception of perceptual experience. Mind 121: 753-771.

Crane, T. 2009. Is perception a propositional attitude? Philosophical Quarterly 59: 452469.

Cussins, A. 1990. The connectionist construction of concepts. In M. Boden, ed., The Philosophy of Artificial Intelligence. Oxford: Oxford University Press.

Cutting, J. \& Vishton, P. 1995. Perceiving layout and knowing distances. In W. Epstein and S. Rogers, eds. Perception of Space and Motion. San Diego, CA: Academic Press, 69-117.

Evans, G. 1982. The Varieties of Reference. Edited by J. McDowell. Oxford: Oxford University Press.

Evans, G. 1985. Molyneux's question. In A. Phillips, ed. The Collected Papers of Gareth Evans London: Oxford University Press.

Ganz, L. 1975. Orientation in visual space by neonates and its modification by visual deprivation. In A. Riesen, ed. The Developmental Neuropsychology of Sensory Deprivation. New York: Academic Press, 169-210.

Goodale, M. 2011. Transforming vision into action. Vision Research 51: 1567-1587.

Granrud, C. \& Yonas, A. 1984. Infants' perception of pictorially specified interposition. Journal of Experimental Child Psychology 37: 500-511.

Granrud, C., Haake, R., \& Yonas, A. 1985. Infants' sensitivity to familiar size: The effect of memory on spatial perception. Perception and Psychophysics 37: 459-466.

Gunther, Y. 2003. Essays on nonconceptual content. The MIT Press.

Grush, R. 2007. Skill theory v2.0: Dispositions, emulation, and spatial perception. Synthese 159: 389-416.

Held, R., \& Hein, A. 1963. Movement-produced stimulation in the development of visually guided behavior. Journal of comparative and physiological psychology, 56: 872-876.

Kalaska, J. 2009. From intention to action: Motor cortex and the control of reaching movements. In D. Sternad, ed., Progress in Motor Control. Berlin: Springer.

Kellman, P. \& Arterberry, M. 2000. The Cradle Of Knowledge: Development of Perception in Infancy. Cambridge, MA: MIT Press. 
Kellman, P. \& Arterberry, M. 2006. Perceptual development. In W. Damon, D. Kuhn, \& R. Siegler, eds. The Handbook of Child Psychology: Cognition, Perception, and Language. Hoboken, NJ: Wiley, 109-160.

Matthen, M. 1988. Biological functions and perceptual content. The Journal of Philosophy 85: 5-27.

Matthen, M. 2006. Review of Action in Perception. Mind 115: 1160-1166.

McDowell, J. 1994. Mind and World. Cambridge, MA: Harvard University Press.

Millikan, R. 1989. Biosemantics. Journal of Philosophy 86: 281-297.

Millikan, R. 2004. Varieties of Meaning. Cambridge, MA: MIT Press.

Millikan, R. 2006. Postulating perceptual representations in a way that actually supports Gibson's central insights. Lecture at the Boston Colloquium for Philosophy of Science, January 30, 2006.

Milner, A.D. and Goodale, M. 1995/2006. The Visual Brain in Action, $2^{\text {nd }}$ edition. Oxford: Oxford University Press.

Náñez, J., \& Yonas, A. 1994. Effects of luminance and texture motion on infant defensive reactions to optical collision. Infant Behavior and Development 17: 165-174.

Noë, A. 2004. Action in Perception. Cambridge, MA: MIT Press.

Noë, A. 2010. Vision without representation. In N. Gangopadhyay, M. Madary, \& F. Spicer, eds. Perception, Action, and Consciousness. Oxford: Oxford University Press, 245-256.

O’Regan, J. K. 2011. Why Red Doesn't Sound Like a Bell: Explaining the Feel of Consciousness Oxford: Oxford University Press.

O’Regan, J. K. and Noe; A. 2001. A sensorimotor account of vision and visual consciousness. Behavioral and Brain Sciences, 24: 939-1031.

Peacocke, C. 1992. A Study of Concepts. Cambridge, MA: MIT Press.

Prinz, J. 2006. Putting the brakes on enactive perception. Psyche, 12: 1-19.

Prinz, J. 2012. The Conscious Brain. Oxford: Oxford University Press.

Schellenberg, S. 2007. Action and self-location in perception. Mind 116: 603-631.

Scott, S. 2008. Inconvenient truths about neural processing in primary motor cortex. Journal of Physiology 586: 1217-1224.

Wu, Wayne 2014. Against division: Consciousness, information and the visual streams. To appear in Mind and Language. 